\title{
Software and data in analytics: lending theory to practice
}

\author{
Maria Petrescu ${ }^{1}$. Anjala S. Krishen ${ }^{1}$
}

Published online: 17 August 2019

(c) Springer Nature Limited 2019

The Journal of Marketing Analytics will feature, starting in this issue, a new section entitled, "Software Review." Based on the format and goals of a book review, our objectives are (1) to expose our readers, practitioners, researchers, and academics to various analytical software developments including their strengths and weaknesses, and (2) to place more attention on the dangers of overemphasizing or misusing digital data analysis. Our first software review is an evaluation of SmartPLS by Sarstedt and Cheah (2019). As the authors state, the software presents a frictionless design, which allows researchers to quickly specify and estimate partial least squares (PLS) path models, focusing more effort on the interpretation of results and theoretical meaning for a project, rather than on the complicated setup of the model and statistical analysis.

Sarstedt and Cheah (2019) note that a statistical program should not be considered rigorous solely because of its complex or complicated interface. They indirectly bring to attention an even more widespread and impactful problem with analytics, namely a pointless and mechanistic focus on data and software. Business researchers and corporate analysts have access to excellent data analysis tools as well as vast amounts of big data from many channels on the Internet and various data collection mechanisms. These could become a shortcut to guide researchers into projects led by data and software availability, rather than proper research methodology including research questions, theory, and even desire for prediction.

Research shows that data, empirical models, and results are not theory; instead, they may describe specific observations of empirical patterns, but theory is still needed which explains the reasoning behind those patterns (Crittenden and Peterson 2011; Sutton and Staw 1995; Weick 1995). The process of theorizing consists of activities such as abstracting, generalizing, relating, selecting, explaining,

Maria Petrescu

maria.petrescu@icn-artem.com

1 ICN Business School Artem, Nancy, France synthesizing, and idealizing (Weick 1995). Therefore, both academics and practitioners should avoid overreliance on analytics data and statistical softwares that may give rise to inexplicable models and atheoretical patterns.

In tandem, confirmatory approaches to analytics and data mining can bring about the risk of confirmation bias. To avoid this potential issue, comparative approaches to judging theories with multiple working hypotheses or explanations can be formulated and tested (Chamberlin 1965; Sternthal et al. 1987); such analyses can be facilitated by software such as SmartPLS. Therefore, when using marketing analytics for research and practice, analysts must find an appropriate balance between data analysis rigor and theoretical relevance (Shrivastava 1987). The interactive dependence between rigorous research and its critical assessment and practical application has characterized progress in other sciences (Popper 1963; Shrivastava 1987).

In this context, Journal of Marketing Analytics calls for additional studies that focus not only on the generalizability of research in the marketing analytics field, but also on its relevance for both marketing researchers and practitioners (Krishen and Petrescu 2018; Petrescu and Krishen 2017). Moreover, a programmatic development of theory and predictive work in the area of marketing analytics could receive more attention. This can have a positive effect on the development of a thorough, rich, integrated research stream in the domain of business analytics. Such research can also help practitioners manage analytics data and software platforms as collective intelligence tools.

\section{References}

Chamberlin, T.C. 1965. The Method of Multiple Working Hypotheses. Science 148 (7): 754-759.

Crittenden, V.L., and R.A. Peterson. 2011. Ruminations About Making a Theoretical Contribution. AMS Review 1 (2): 67-71. https://doi. org/10.1007/s13162-011-0014-1. 
Krishen, A.S., and M. Petrescu. 2018. Marketing Analytics: Delineating the Field While Welcoming Crossover. Journal of Marketing Analytics 6 (4): 117-119.

Petrescu, M., and A.S. Krishen. 2017. Marketing Analytics: From Practice to Academia. Journal of Marketing Analytics 5 (1): 45-46.

Popper, K. 1963. Conjectures and Refutations: The Growth of Scientific Knowledge. London: Routledge.

Sarstedt, M., and J.-H. Cheah. 2019. Partial Least Squares Structural Equation Modeling Using SmartPLS: A Software Review. Journal of Marketing Analytics. https://doi.org/10.1057/s41270-01900058-3.

Shrivastava, P. 1987. Rigor and Practical Usefulness of Research in Strategic Management. Strategic Management Journal 8: 77-92.

Sternthal, B., A.M. Tybout, and B.J. Calder. 1987. Confirmatory Versus Comparative Approaches to Judging Theory Tests. Journal of Consumer Research 14: 114-125.

Sutton, R.I., and B.M. Staw. 1995. What Theory is Not. Administrative Science Quarterly 40: 371-384.

Weick, K.E. 1995. What Theory is Not, Theorizing Is. Administrative Science Quarterly 40: 385-390.

Publisher's Note Springer Nature remains neutral with regard to jurisdictional claims in published maps and institutional affiliations.

Dr. Maria Petrescu is an Associate Professor of Marketing at ICN Business School Artem, Nancy, France and faculty member at Colorado State University, Global Campus, USA. Her research interests are digital marketing and marketing analytics and she has a Ph.D. in Business Administration and Marketing from Florida Atlantic University. She participated and published in prestigious conferences and publications, including the Journal of Marketing Management, Journal of Retailing and Consumer Services, Journal of Product and Brand Management and the Journal of Internet Commerce. In 2014 she also published a book on Viral marketing and social networks.

Anjala S. Krishen Professor of Marketing and International Business and Special Advisor to the Dean for Research at University of Nevada, Las Vegas, has a B.S. in Electrical Engineering from Rice University, and an M.S. Marketing, MBA, and Ph.D. from Virginia Tech. Krishen held management positions for 13-years before pursuing a doctorate. As of 2019, she has published over 50 peer-reviewed journal papers in journals including Journal of Business Research, Psychology \& Marketing, Information \& Management, European Journal of Marketing, Journal of Travel \& Tourism Marketing, and Journal of Marketing Education. In 2016, she gave a TEDx talk (at UNR) titled, "Opposition: The light outside of the dark box," and a UNLV Creates speech entitled, "Consuming to Creating, Watching to Doing, Seeing to Being." To date, she has completed over 55 marathons, seven ultramarathons, three 100 milers, and has a black belt in Taekwondo. 